\title{
Studying the Effects of Adding Silica Sand Nanoparticles on Epoxy Based Composites
}

\author{
Tahir Ahmad, ${ }^{1}$ Othman Mamat, ${ }^{2}$ and Rafiq Ahmad ${ }^{1}$ \\ ${ }^{1}$ Department of Metallurgy and Materials Engineering, College of Engineering and Emerging Technologies, \\ University of the Punjab, Lahore, Pakistan \\ ${ }^{2}$ Mechanical Engineering Department, Universiti Teknologi PETRONAS, Bandar Seri Iskandar, 31750 Tronoh, Perak, Malaysia
}

Correspondence should be addressed to Tahir Ahmad; tahirengg4051@yahoo.com

Received 10 December 2012; Accepted 24 December 2012

Academic Editor: Amir Kajbafvala

Copyright (C) 2013 Tahir Ahmad et al. This is an open access article distributed under the Creative Commons Attribution License, which permits unrestricted use, distribution, and reproduction in any medium, provided the original work is properly cited.

\begin{abstract}
The research about the preparation of submicron inorganic particles, once conducted in the past decade, is now leading to prepare polymer matrix composite (PMC) reinforced with nanofillers. The objective of present research is to study the modified effects of reinforcement dispersion of nanoparticle silica in epoxy resin on the physical properties, mechanical and thermal behaviour, and the microstructure of resultant composites. Stirrer mixing associated with manual mixing of silica sand nanoparticles (developed in our earlier research) (Ahmad and Mamat, 2012) into epoxy was followed by curing being the adopted technique to develop the subject nanocomposites. Experimental values showed that $15 \mathrm{wt} . \%$ addition of silica sand nanoparticles improves Young's modulus of the composites; however, a reduction in tensile strength was also observed. Number of holes and cavities produced due to improper mixing turn out to be the main cause of effected mechanical properties. Addition of silica sand nanoparticles causes a reduction in degree of crystallinity of the nanocomposites as being observed in differential scanning calorimetry (DSC) analysis.
\end{abstract}

\section{Introduction}

Nowadays industrial and academic research laboratories are focusing much of their efforts to develop and improve physical, mechanical, and electrical properties of polymer nanocomposites. Their interest to develop such composites is mainly because of the fact that nanoparticles present a high surface-to-volume ratio which may induct unique properties to these nanocomposites as compared to macro-scale composites [1]. Andritsch et al. [2] prepared nanocomposites filled with $\mathrm{SiO}_{2}, \mathrm{Al}_{2} \mathrm{O}_{3}$, and $\mathrm{AIN}$ with an average particles size from $22 \mathrm{~nm}$ to $10 \mathrm{~nm}$ and studied the nanoparticles dispersion and DC breakdown strength. They observed the highest DC breakdown strength for $0.5 \mathrm{wt} . \%$ for two component system. It was also noticed that the DC breakdown strength increased with $10 \mathrm{wt} . \%$ as compared to 2 and $5 \mathrm{wt} . \%$ and again decreased with $15 \mathrm{wt} . \%$ nano-fillers. Yasmin et al. [3] studied the dispersion of clay nanoparticles in epoxy-based composites using a three roll mill with the concentration of $1-10 \mathrm{wt} . \%$. This technique was found highly efficient and environmentally friendly due to excellent dispersion of nanoparticles within a short time. Elastic modulus was improved up to $80 \%$ with $10 \mathrm{wt} . \%$ addition of clay nanoparticles in epoxy. Absence of any improvement in tensile strength of the nanocomposites over pure epoxy was due to the clustering of nanoparticles and/or to the occasional occurrence of nano- to microsize voids in the microstructure. Li et al. [4] prepared the Epoxy nanocomposites with exfoliated nanoclay and a novel ultrafine full-vulcanized powdered rubber. The morphology of the epoxy/rubber/clay nanocomposites has been studied using X-ray diffraction (XRD) and transmission electron microscopy (TEM). Their study showed that the unmodified clay was fully exfoliated and uniformly dispersed in the resulting nanocomposite and found that the impact strength of this special epoxy/rubber/clay nanocomposite increased up $107 \%$ over the neat epoxy resin. Thermal analyses showed that thermal stability of the nanocomposite was much better than that of epoxy nanocomposite based on organically modified clay. Damian et al. [5] synthesized epoxy-based nanocomposites reinforced with multiwalled 


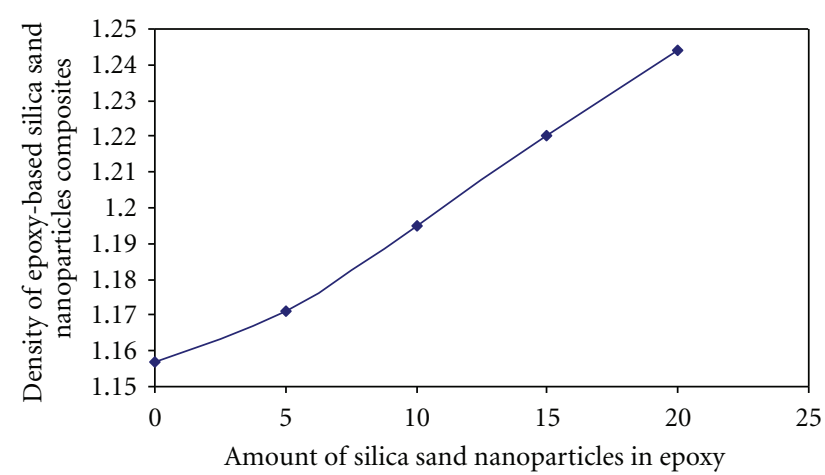

Figure 1: Density analyses of epoxy-SiO $\mathrm{S}_{2}$ composites.

carbon nano-tubes (MWNT). They functionalized MWNTs in order to increase the dispersion in the polymer matrix and thus to ensure good adhesion between the two components. Their study showed that the structure of amine MWNTB100 exhibit compatibility with the epoxy matrix. However, the higher thermostability was achieved by the composite based on MWNTCOOH as observed from TGA. Frache et al. [6] prepared the epoxy based nanocomposites reinforced with home-made hydrotalcites (HTlc) and montmorillonite(MMT-)type layered silicates and studied the morphology, dispersion and thermal analysis of the nanocomposites. Their research showed possibility to obtain nano-structured materials, characterized by the resin intercalation into HTlc galleries, by using a proper exchange of the pristine hydrotalcite with stearate anions. The thermal analysis indicated that nanocomposites based on HTlc were prone to decompose, both in air and nitrogen, while in the case of the nanocomposite based on the organophilic MMT a slight improvement was found in air. Jordan et al. [7] studied the effect of addition of micron and nanosized silica inclusions on polyurethane matrix and found it as an increment in density as the filler content increased. He investigated that the composite density further can be increased with micronsized inclusions as compared to the density for the nanosized inclusions. In above studies, no body tried to utilize silica sand nanoparticles as reinforcement agents in epoxy based composites. Exclusively, the objective of present research is to fill this gap and study the effect of addition of silica sand nanoparticles on epoxy based composites.

\section{Experimental Work}

The processing and characterization of silica sand nanoparticles have already been discussed in our earlier papers [8]. Before mixing with epoxy resin (E-51), silica sand nanoparticles were dried at $120^{\circ} \mathrm{C}$ to remove any moisture for 5 hours. The silica sand nanoparticles were mixed with epoxy using stirrer and manual mixing for several hours. The resultant mixture was degassed and cured in steel mould at $120^{\circ} \mathrm{C}$ to form dog-bone-shaped samples (ASTM D638-97). ASTM D790-03 standard was used to develop flexural test specimens. The Universal Tensile Testing machine $(5 \mathrm{KN})$ LLOYD Instruments, LR $5 \mathrm{~K}$ was engaged to determine the

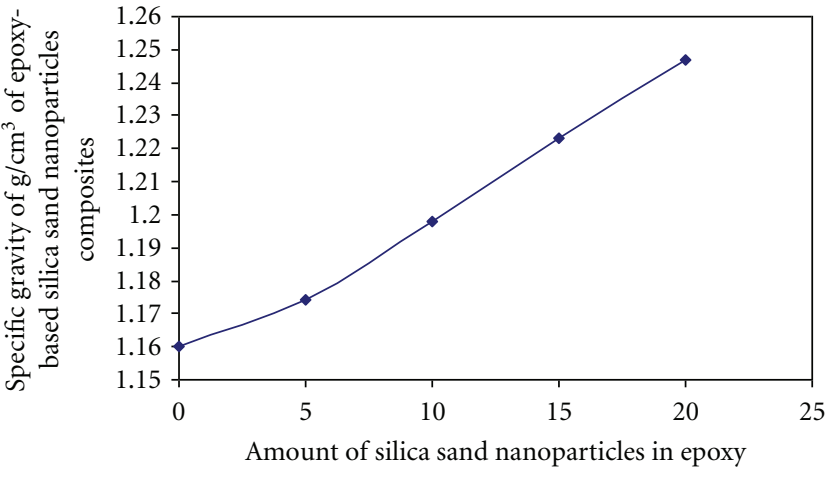

FIGURE 2: Specific gravity analyses of epoxy- $\mathrm{SiO}_{2}$ composites.

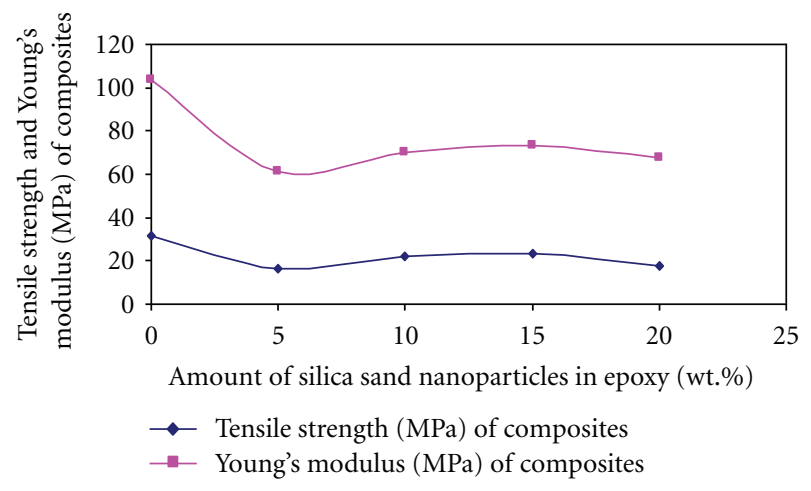

Figure 3: Tensile strength and Young's modulus of epoxy-SiO composites.

tensile and flexural properties of the composites with a crosshead speed of $50 \mathrm{~mm} / \mathrm{min}$. ASTM D 792-08 standard was used to determine the densities of epoxy based composites. Differential scanning calorimeter (DSC) in nitrogen atmosphere was incorporated to analyse the thermal properties of the epoxy based composites. A $5 \mathrm{mg}$ weight sample was prepared to obtain the scans between 40 to $210^{\circ} \mathrm{C}$ wit a heating rate of $10^{\circ} \mathrm{C} / \mathrm{min}$.

\section{Results and Discussion}

3.1. Processing of Tronoh Silica Sand. The silica sand originated naturally from Tronoh Perak, Malaysia was washed with water to remove any clay particles followed by drying it in an oven at $120^{\circ} \mathrm{C}$. The dried silica sand was meshed about $<600 \mu \mathrm{m}$ using sieve analysis. The $<600 \mu \mathrm{m}$ size of natural silica sand was ground to nanoparticles using dry ball milling with zirconia balls as grinding media with different steps of sieve analysis. This high-energy milling was known as one of the "top-down" nanoparticles type approach, which generally relies on physical methods for their production. Different particles sizes went through a precise sieve analysis (Sieve Shaker (EFL2000). The analysis of silica sand nanoparticles had been verified using the ZetaSizer, Nano ZS (ZEN 3600) (MALVERN) analyzer. The nanoparticles results were also checked microscopically through FESEM. 


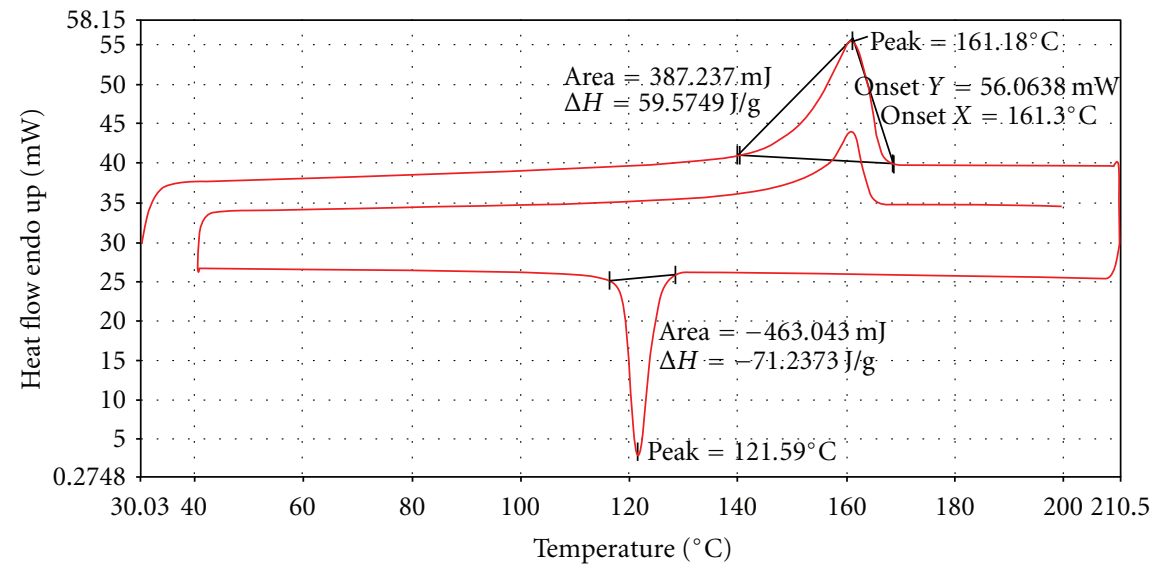

FIGURE 4: DSC curves of crystallization of epoxy- $\mathrm{SiO}_{2}$ composites.

The chemical composition of silica sand nanoparticles was analyzed adopting XRF technique [8].

\subsection{Characterization of the Epoxy-Silica Sand Nanoparticles Composites}

3.2.1. Density and Specific Gravity Determination of EpoxySilica Nanoparticles Composites. The silica sand being denser as compared to epoxy may cause an enhancement in density of epoxy when added as reinforcement as shown in Figure 1. For every $5 \mathrm{wt}$.\% increase in weight of silica sand nanoparticles, the density of epoxy raised with an average incremental value of $1.8 \%$. Temperature recorded during testing procedure remained as $22.6^{\circ} \mathrm{C}$. The inclusions of silica nanoparticles when added to polymer tended to create a linkage of bonding between $\mathrm{SiO}_{2}$ and polymer which some time results in higher density of the composites.

Results obtained above may actually be expanded to get specific gravity values for each sample. The density and specific gravity were determined using D 792-08 ASTM standard. Specific gravity, or relative density, increases in accordance to sample density as well as wt\% increment of silica sand nanoparticles. An increase between 2\%-6\% can be seen by comparing silica sand nanoparticles added epoxy with its pure form as control element. For every 5\% increase in weight of silica sand nanoparticles, it can be found that specific gravity increased by an average value of $1.8 \%$, which is the same compared to density measurement. The results of specific gravities are shown in Figure 2.

3.2.2. Mechanical Properties of the Epoxy-Silica Sand Nanoparticles Composites. The properties of the composites depend upon the method of dispersion of particles, aggregation of particles, and interaction between particles and polymers. The thickness and density of the interphase developed between two constituents depend on the interaction between particles and polymer [7]. Interparticle distance also plays an important role in the interphase behaviour and properties of the composites. Tensile properties of the composites are mostly affected by the materials, method, specimen condition and preparation, and also by percentage of the reinforcement [9]. For the comparative testing of materials, the preparation of samples and adopted method are very important to get relatively same properties of the composites. Silica nanoparticles, if not properly mixed with the epoxy, cause voids and increase level of porosity inside the system. This is the reason why pure epoxy exhibited highest value of tensile strength and Young's modulus, and why this strength got reduced when silica nanoparticles between $15 \mathrm{wt} . \%$ and $20 \mathrm{wt} . \%$ dispersed in it. The mechanical properties of the epoxy-silica sand nanoparticles composites are shown in Figure 3. As wt.\% of silica sand nanoparticles increases, tensile strength as well as Young's modulus also rises. These numbers conversely drop when $20 \mathrm{wt} \%$ of silica sand nanoparticles is introduced to system. Nature of interface is important in producing high-performance epoxy-nanosilica composites [10]. Better tensile properties are achieved when the samples have good interface between matrix and filler because the applied load mostly transferred through the filler via interface.

\subsubsection{Thermal Analysis of the Epoxy-Silica Sand Nanoparticles} Composites. The thermal analysis of epoxy- $\mathrm{SiO}_{2}$ nanocomposites was performed using DSC technique as shown in Table 1. Neat epoxy showed the values of crystallization temperature between 111.12 and $110.32^{\circ} \mathrm{C}$; however, for 20 wt.\% of silica sand nanoparticles addition to epoxy, the values remain between 121.59 and 119.97. The increase in weight percentage of silica sand nanoparticles to epoxy increases the crystallization temperature; however, it reduces the percentage crystallinity of the nanocomposites as shown in Figure 4 DSC curves. Melting endotherms showed a slight difference for all samples as observed in DSC thermograms and the same results were also found by other researcher using different kinds of nanoparticles [10]. Built-in software 
TABLE 1: DSC analysis of epoxy-silica sand nanoparticles composites.

\begin{tabular}{|c|c|c|c|c|c|c|}
\hline Composites & $\begin{array}{c}\text { Crystallization } \\
T_{c} \cdot \text { (onset) } \\
\left.\text { ( }{ }^{\circ} \mathrm{C}\right)\end{array}$ & $\begin{array}{c}\text { Crystallization } \\
T_{c} \text {. (peak) } \\
\left.\text { ( }{ }^{\circ} \mathrm{C}\right)\end{array}$ & $\begin{array}{c}\text { Melting } \\
T_{m} \cdot \text { (onset) } \\
\left.\text { ( }{ }^{\circ} \mathrm{C}\right)\end{array}$ & $\begin{array}{c}\text { Melting } \\
T_{m} \cdot(\text { peak }) \\
\left({ }^{\circ} \mathrm{C}\right)\end{array}$ & $\Delta H(\mathrm{~J} / \mathrm{g})$ & $\begin{array}{c}\text { Crystallinity } \\
(\%)\end{array}$ \\
\hline Pure epoxy & 110.32 & 111.12 & 160.20 & 161.14 & 250.774 & 86.8 \\
\hline 5 wt. $\%$ silica sand + epoxy & 112.34 & 113.40 & 160.33 & 161.40 & 240.523 & 83.5 \\
\hline 10 wt.\% silica sand + epoxy & 115.44 & 116.20 & 160.45 & 161.21 & 239.804 & 80.3 \\
\hline 15 wt.\% silica sand + epoxy & 117.95 & 118.60 & 179.64 & 161.46 & 237.495 & 79.5 \\
\hline 20 wt. $\%$ silica sand + epoxy & 119.97 & 121.59 & 138.30 & 145.55 & 230.444 & 77.6 \\
\hline
\end{tabular}

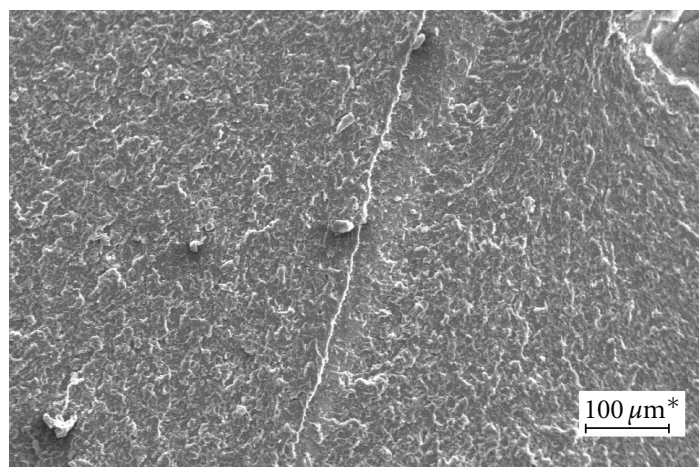

(a)

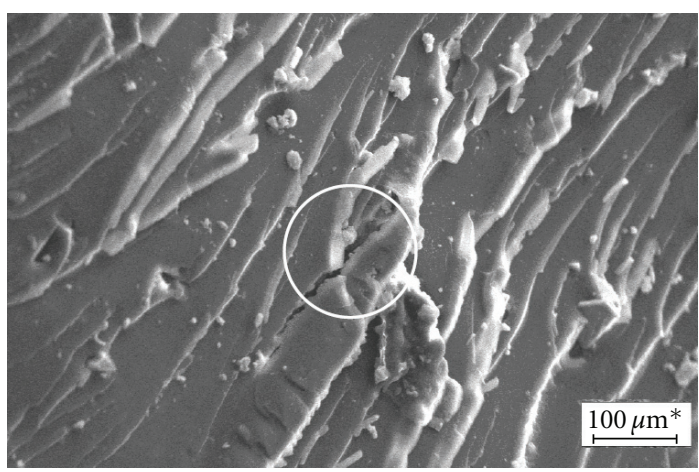

(c)

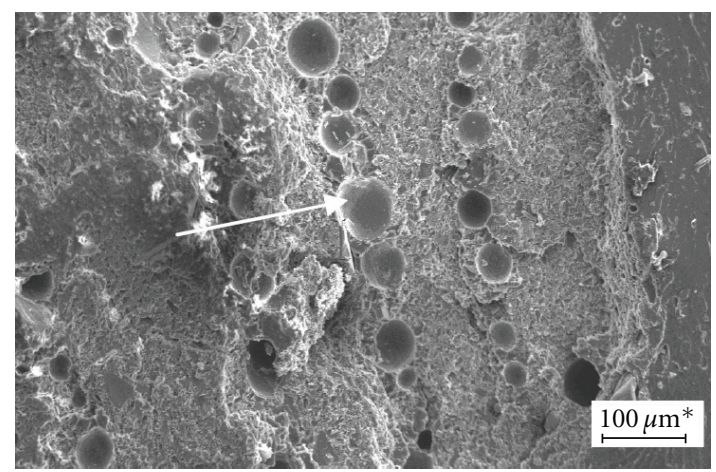

(b)

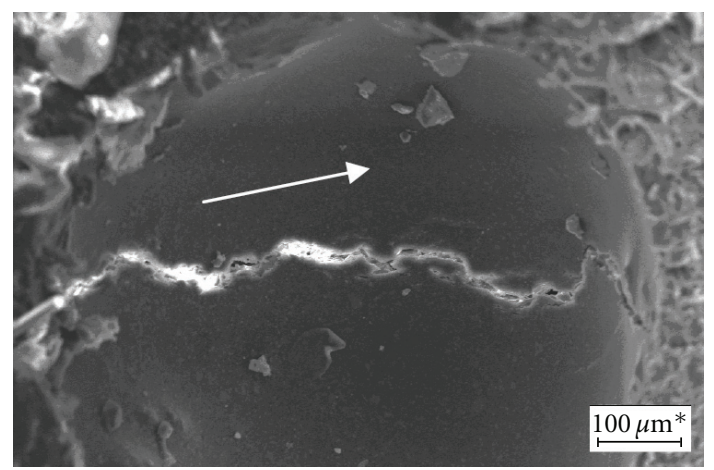

(d)

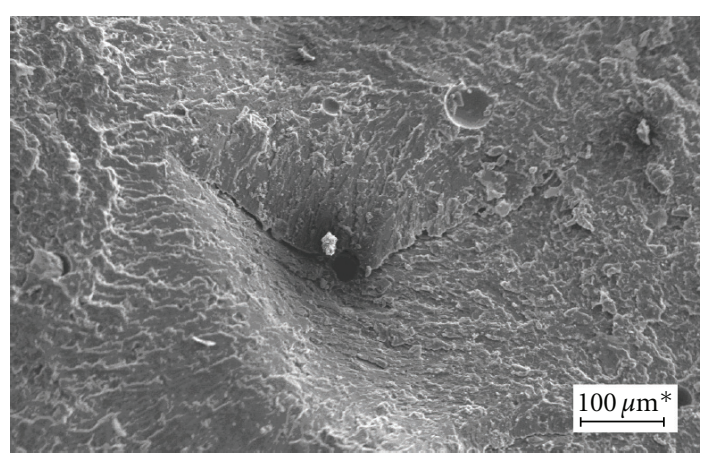

(e)

Figure 5: Fracture surface analysis of pure epoxy, epoxy- $\mathrm{SiO}_{2}$ nanoparticles composites with (a) pure, (b) 5 wt.\% $\mathrm{SiO}_{2}$, (c) 10 wt.\% $\mathrm{SiO}_{2}$, (d) 15 wt. $\% \mathrm{SiO}_{2}$, (e) 20 wt. $\% \mathrm{SiO}_{2}$. 
as shown in (1) below was used to determine the heat of fusion $(\Delta H)$ from the scans as follows:

$$
X_{\mathrm{DSC}}=\frac{\Delta H_{\text {sample }}}{293} \text {. }
$$

The reduction in degree of crystallinity was mainly due to reducing trend of heat of fusion from $5 \mathrm{wt} . \%$ to $20 \mathrm{wt} . \%$ of silica sand nanoparticles in epoxy. The same results were also discussed by some other researchers $[11,12]$.

\subsubsection{Fracture Surfaces SEM Analysis of Tensile Samples of} Epoxy-SiO $\mathrm{S}_{2}$ Composites. For pure epoxy, Figure 5(a) shows a brittle fracture which is due to quite surface roughness, and river line pattern in fracture surface [10]. A lot of holes and cavities can be seen in Figure 5(b), which could be due to other small molecular chemical compounds adhered to the silica nanoparticles. This behaviour confirms the reason, as discussed earlier, why tensile strength drops drastically between pure epoxy and 5\% silica nanoparticles added to it. In Figure 5(c), tiny crack lines are visible and the arrow indicates the slow propagating crack area. Circled crack propagation in Figure 5(c) justifies that the crack direction is from top to bottom in the micrograph. Figures 5(d) and 5(e) signify crack propagation as a result from cavities and holes formed, due to improper mixture process. The white zones in SEM analysis show that the deformation and cohesive failure of the composites is because of the silica sand nanoparticles surrounds a large part of the polymer matrix. Decreasing trend of mechanical properties is due to agglomeration of silica sand nanoparticles in epoxy as shown in SEM results images.

\section{Conclusion}

Epoxy- $\mathrm{SiO}_{2}$ nanocomposites were successfully produced using Tronoh silica sand nanoparticles as reinforcement. The density of the epoxy- $\mathrm{SiO}_{2}$ nanocomposites was increased from $1.157 \mathrm{~g} / \mathrm{cm}^{3}$ to $1.244 \mathrm{~g} / \mathrm{cm}^{3}$ with an average increment of $1.796 \%$. The mechanical properties of the nanocomposites decrease with the addition of silica sand nanoparticles due to improper mixing of the nanoparticles. SEM micrograph showed white and agglomerate zones on fracture surfaces which indicate that silica sand nanoparticles are not homogeneously dispersed in epoxy. A reduction in degree of crystallinity in epoxy based nanocomposites was observed with increasing trend of silica sand nanoparticles addition in epoxy as shown by DSC analysis.

\section{Acknowledgments}

The authors would like to thank the Universiti Teknologi PETRONAS Perak, Malaysia and University of the Punjab Lahore Pakistan for providing the necessary support to complete this research.

\section{References}

[1] J. Gonzalez-Benito and D. Olmos, "Efficient dispersion of nanoparticles in the thermoplastic polymers," Society of Plastics Engineers, Plastics Research Online, 2010.

[2] T. Andritsch, R. Kochetov, Y. T. Gebrekiros, U. Lafont, P. H. F. Morshuis, and J. J. Smit, "Synthesis and dielectric properties of epoxy based nanocomposites," in Proceedings of the Annual Report Conference on Electrical Insulation and Dielectric Phenomena (CEIDP '09), pp. 523-526, October 2009.

[3] A. Yasmin, J. L. Abot, and I. M. Daniel, "Processing of clay/ epoxy nanocomposites by shear mixing," Scripta Materialia, vol. 49, no. 1, pp. 81-86, 2003.

[4] B. Li, X. Zhang, J. Gao et al., "Epoxy based nanocomposites with fully exfoliated unmodified clay: mechanical and thermal properties," Journal of Nanoscience and Nanotechnology, vol. 10, no. 9, pp. 5864-5868, 2010.

[5] C. M. Damian, A. M. Pandele, C. Andronescu, A. Ghebaur, S. A. Garea, and H. Iovu, "Epoxy-based nanocomposites reinforced with new amino functionalized multi-walled carbon nanotubes," Fullerenes Nanotubes and Carbon Nanostructures, vol. 19, no. 3, pp. 197-209, 2011.

[6] A. Frache, O. Monticelli, M. Nocchetti, G. Tartaglione, and U. Costantino, "Thermal properties of epoxy resin nanocomposites based on hydrotalcites," Polymer Degradation and Stability, vol. 96, no. 1, pp. 164-169, 2011.

[7] J. Jordan, K. I. Jacob, R. Tannenbaum, M. A. Sharaf, and I. Jasiuk, "Experimental trends in polymer nanocomposites-a review," Materials Science and Engineering A, vol. 393, no. 1-2, pp. 1-11, 2005.

[8] T. Ahmad and O. Mamat, "Tronoh silica sand nanoparticle production and applications design for composites," Defect and Diffusion Forum, vol. 330, pp. 39-47, 2012.

[9] American Standard of Testing Material (ASTM), Standard Test Method for Tensile Properties of ReinForced Thermosetting Plastics Using Straight Sided Specimens, ASTM International, West Conshohocken, Pa, USA, 2004.

[10] Y. Zheng, K. Chonung, G. Wang, P. Wei, and P. Jiang, "Epoxy/nano-silica composites: curing kinetics, glass transition temperatures, dielectric, and thermal-mechanical performances," Journal of Applied Polymer Science, vol. 111, no. 2, pp. 917-927, 2009.

[11] K. Chrissafis, K. M. Paraskevopoulos, E. Pavlidou, and D. Bikiaris, "Thermal degradation mechanism of HDPE nanocomposites containing fumed silica nanoparticles," Thermochimica Acta, vol. 485, no. 1-2, pp. 65-71, 2009.

[12] M. Joshi and B. S. Butola, "Studies on nonisothermal crystallization of HDPE/POSS nanocomposites," Polymer, vol. 45, no. 14, pp. 4953-4968, 2004. 

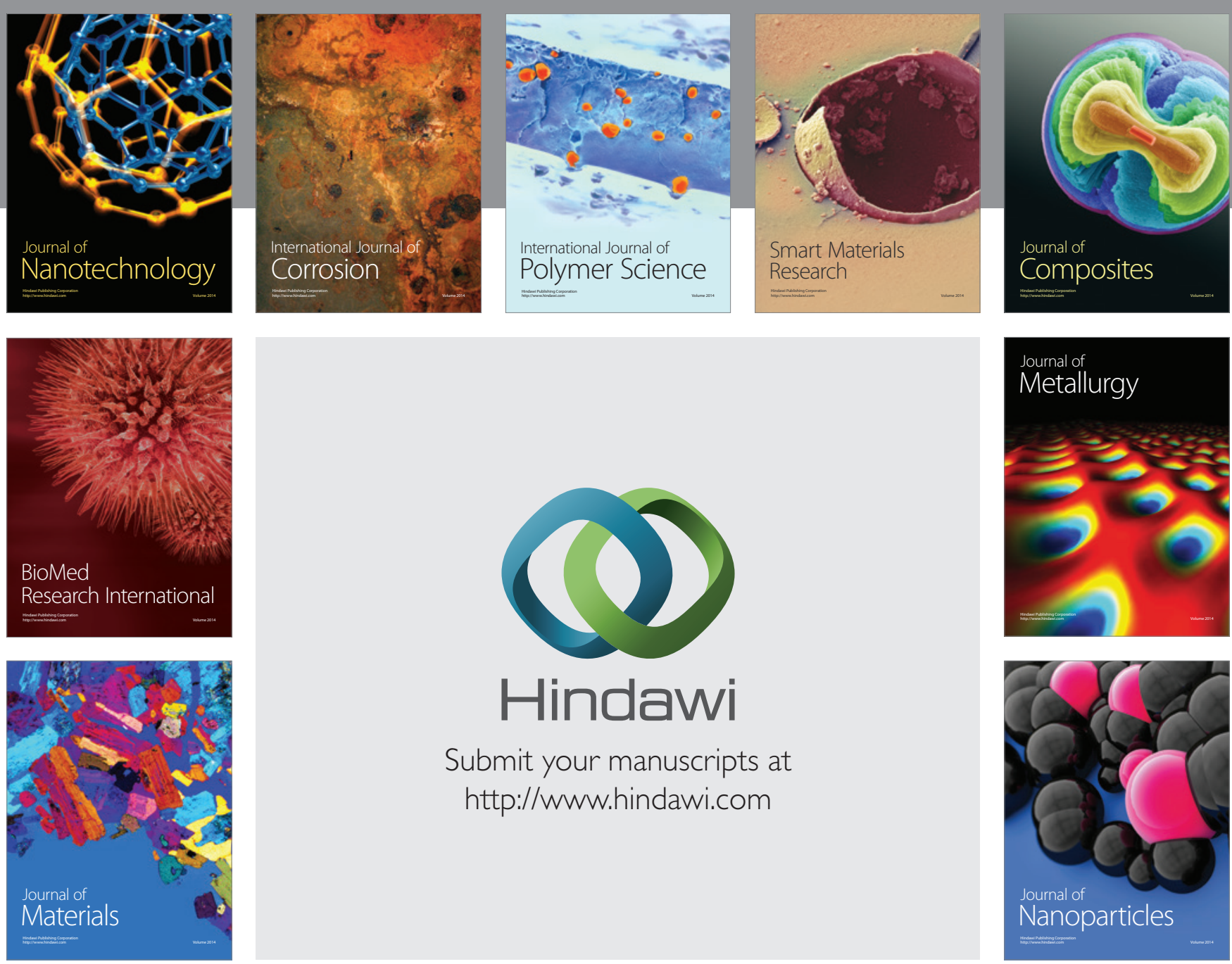

Submit your manuscripts at http://www.hindawi.com
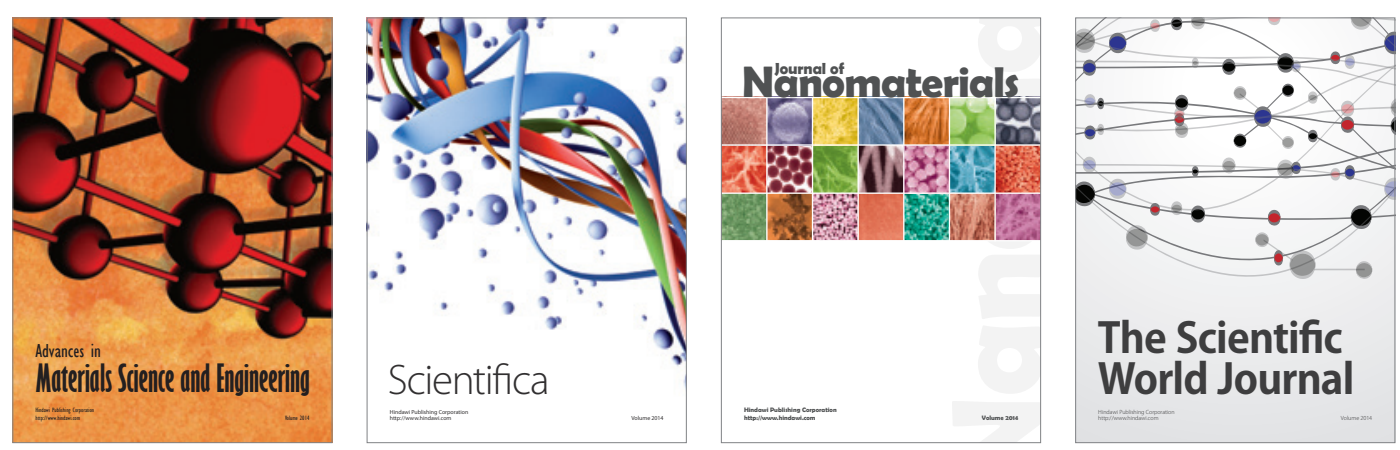

\section{The Scientific World Journal}
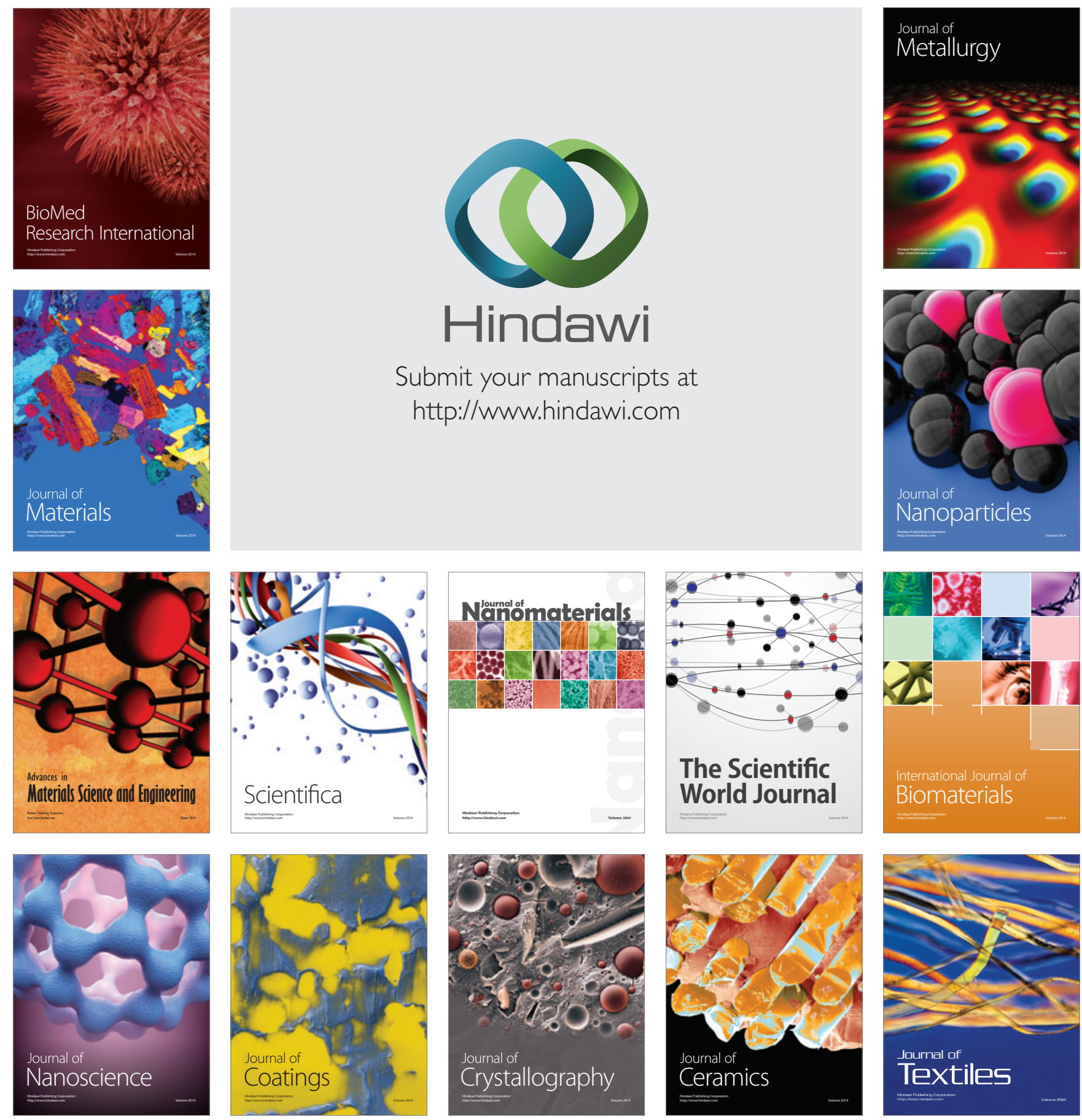